\title{
Karakterisasi Koleksi Plasma Nutfah Tomat Lokal dan Introduksi
}

\section{Characterization of Germplasm Collection in Local and Introduction of Tomato}

\author{
Nazirwan $^{1}$, Anung Wahyudi ${ }^{1}$, dan Dulbari ${ }^{2}$ \\ ${ }^{1}$ Program D4 Teknologi Perbenihan, Jurusan Budidaya Tanaman Pangan, \\ ${ }^{2}$ Program D3 Produksi Tanaman Pangan, Jurusan Budidaya Tanaman Pangan, \\ Politeknik Negeri Lampung, Jln. Soekarno-Hatta No.10 Rajabasa, Bandar Lampung \\ E-mail : anung@polinela.ac.id
}

\begin{abstract}
The function of plant introductions among others is to obtain new cultivars. After the introduction of plants through the process of adaptation and selection can be used as material crosses with cultivars that have adapted well. A cultivar is said superior when it has a high yield, good fruit quality, resistance to pest attack (plant pests), and able to adapt to various environments grow. The aim of this study was obtain a description, test and compare the yield and quality potential of eight varieties of tomatoes grown in the lowland which are expected to serve as a cross parent material in breeding programs. The experiment was arrange by randomized block design with three replications. The data were analyzed using F-test and the results were significantly midpoint test using LSD test at 5\% level. Based on observations on eight strains of local tomatoes and introductions have descripted then selected three strains of tomato introductions which has the form of a round (TM 130804, TM 130805, TM 130806) as well as the introduction of two strains of tomato fruit has an oval shape (TM 130801 and TM 130803 ) that can be used as breeding material further.
\end{abstract}

Keywords : collection, germplasm, tomato.

Diterima: 29-11-2013, disetujui 17-01-2014

\section{PENDAHULUAN}

Tomat merupakan tanaman sayuran penting dan telah banyak diusahakan sebagai tanaman pekarangan maupun secara komersial yang pembudidayaannya dapat dilakukan di lahan dan rumah kaca. Tomat (Solanum lycopersicum L.) memegang peranan yang penting dalam pemenuhan gizi masyarakat. Buah tomat banyak mengandung zat-zat yang berguna bagi tubuh manusia. Likopena (lycopene) berperan sebagai antioksidan. Kandungan gizi lainnya adalah vitamin C, A, K dan mineral. 

Banyak usaha dilakukan manusia untuk menghasilkan jenis tomat dengan perubahan sifat yang diinginkan.

Fungsi introduksi tanaman antara lain adalah untuk memperoleh kultivar baru. Tanaman introduksi setelah melalui proses adaptasi dan seleksi dapat dijadikan sebagai bahan persilangan dengan kultivar yang sudah beradaptasi dengan baik. Suatu kultivar dikatakan unggul bila telah memiliki daya hasil tinggi, kualitas buah baik, tahan terhadap serangan OPT (organisme pengganggu tanaman), dan mampu beradaptasi pada berbagai lingkungan tumbuh (Yusdar et al., 1992; Nurtika dan Suwandi, 1992). Varietas tomat yang ada sampai saat ini pengembangannya masih bersifat nasional dan belum ada yang spesifik agroklimat. Hal ini mengakibatkan produktivitas tomat belum optimal. Komoditas tomat yang beradaptasi luas akan lebih mudah pengembangannya dibandingkan komoditas yang menghendaki lingkungan spesifik (Duriat, 1997).

Komoditas tomat yang beradaptasi luas akan lebih mudah pengembangannya dibanding komoditas sayuran yang menghendaki kondisi lingkungan tertentu. Keterbatasan areal budidaya tanaman tomat di dataran tinggi dan sangat beresiko terjadinya degradasi lingkungan. Hal ini jelas merupakan ancaman bagi kelangsungan sistem pertanian dan tantangan bagi upaya konservasinya.

Upaya pengembangan tomat dari tahun ke tahun terus meningkat. Hal ini memberikan indikasi bahwa potensi pengembangan tomat di dataran rendah sangat prospektif. Namun masih terdapat berbagai kendala dalam budidaya tomat di dataran rendah, antara lain : (i) Kesesuaian iklim. Tomat tumbuh baik pada temperatur antara $65-90{ }^{\circ} \mathrm{F}\left(18,3-32,2{ }^{\circ} \mathrm{C}\right)$ dengan kelembaban udara sekitar $95 \%$ (Jones, 2008), (ii) Produktivitas. Perlu adanya peningkatan produktivitas tomat dataran rendah. Saat ini tanaman tomat dataran rendah memiliki produktivitas lebih rendah dibandingkan dengan tomat yang dibudidayakan di dataran tinggi, (iii) Kualitas Buah. Tomat yang ideal memiliki ukuran yang seragam, warna buah merata, berdaging buah tebal dan cukup keras, serta tinggi akan kandungan nutrisi, (iv) Ketahanan terhadap hama dan penyakit. Tanaman tomat dataran rendah rentan terhadap penyakit, curah hujan tinggi disertai temperatur tinggi mudah terserang Pseudomonas solanacearum (penyakit layu bakteri), sehingga hasil buahnya akan rendah.

Upaya perakitan varietas unggul baru perlu dilakukan untuk mencari varietas tomat unggul. Varietas-varietas tersebut diharapkan dapat dibudidayakan dengan baik pada dataran rendah, dengan produktivitas tinggi, tahan terhadap hama dan penyakit, yang penting pula memiliki tekstur kulit yang lebih tebal sehingga saat proses pengangkutan, buah tidak mudah rusak. Masalah yang dihadapi dalam penggunaan galur-galur potensial adalah fenomena perbedaan hasil bila ditanam pada lingkungan yang berbeda. Untuk itu diperlukan pengujian untuk mengetahui karakteristik, daya hasil dan kualitas varietas tersebut dengan kondisi lingkungan yang sesuai dengan kondisi tempat suatu varietas yang akan dibudidayakan.

Penelitian ini bertujuan untuk mendapatkan deskripsi, menguji serta membandingkan daya hasil dan kualitas delapan varietas potensial tomat yang ditanam di dataran rendah yang diharapkan dapat dijadikan sebagai tetua bahan persilangan dalam program pemuliaan.

\section{METODE}

Bahan yang diuji terdiri dari enam galur/nomer introduksi yaitu TM130801, TM130802, TM130803, TM130804, TM130805 dan TM130806 serta dua galur pembanding yaitu varietas rampai hibrida (TM130807) dan rampai lokal (TM130808). Alat yang digunakan dalam penelitian meliputi ajir, meteran, tray, alat tulis, kamera, dan alat-alat pertanian. Pupuk yang digunakan adalah pupuk 
kandang, Urea, NPK mutiara, SP-36 dan KCl. Untuk melindungi tanaman dari serangan hama dan penyakit digunakan, pestisida nabati, furadan 3G, curacron, antracol, dan dithane M-45.

Penelitian menggunakan Rancangan Kelompok Lengkap Teracak (RKLT) satu faktor dengan enam varietas tomat introduksi dan dua varietas pembanding sebagai perlakuan dengan tiga ulangan sehingga terdapat 24 satuan percobaan. Setiap satuan percobaan terdapat 10 tanaman dengan tiga tanaman contoh, jarak tanam 50 x $60 \mathrm{~cm}$. Secara statistik model rancangan yang digunakan adalah :

Keterangan:

$$
Y i j=\mu+\tau i+\beta j+\varepsilon i j
$$

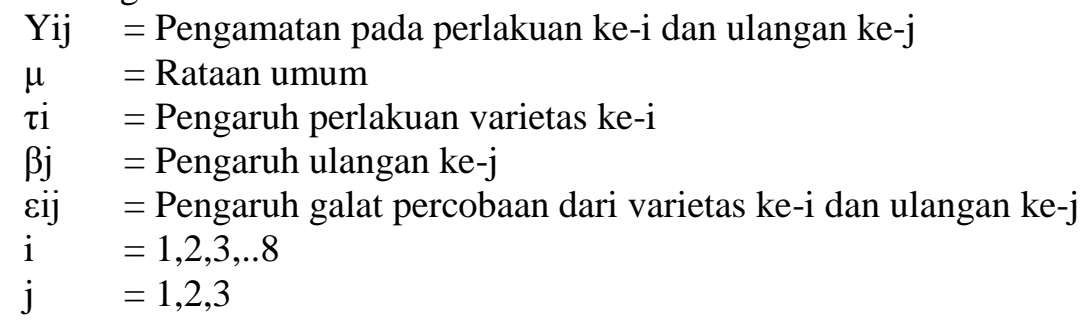

Data yang diperoleh dianalisis dengan menggunakan uji-F dan apabila hasil yang diperoleh berpengaruh nyata maka dilakukan uji nilai tengah dengan menggunakan uji BNT pada taraf $5 \%$.

Beberapa peubah yang diamati pada penelitian ini adalah jenis atau tipe, tipe tumbuh, umur berbunga, umur tanaman atau panen, warna buah masak, bentuk buah, warna batang, tipe tanaman, tinggi tanaman, jumlah buah/tandan, jumlah tandan/tanaman, jumlah buah/tanaman, bobot per buah, bobot buah/tanaman, dan ukuran buah.

\section{HASIL DAN PEMBAHASAN}

\section{Deskripsi delapan galur/nomor tomat lokal dan introduksi}

Berdasarkan data deskripsi delapan galur/nomor tanaman tomat pada penelitian ini menunjukkan bahwa enam galur tomat introduksi adalah tipe cherry dan indeterminate, sedangkan dua galur tomat lokal adalah tipe rampai dan determinate. Pada parameter umur berbunga menunjukkan bahwa seluruh galur memiliki umur berbunga antara 28-31 HST dan umur tanaman 124 HST pada tomat introduksi dan 92 HST pada tomat lokal (Tabel 1).

Tabel 1. Deskripsi delapan galur/nomor tomat lokal dan introduksi

\begin{tabular}{ccccccc} 
No & Galur & Asal & Jenis/Tipe & $\begin{array}{c}\text { Tipe } \\
\text { tumbuh }\end{array}$ & $\begin{array}{c}\text { Umur } \\
\text { Berbunga } \\
(\text { HST })\end{array}$ & $\begin{array}{c}\text { Umur } \\
\text { tanaman } \\
(\text { HST })\end{array}$ \\
\hline 1 & TM130801 & Jepang & Cherry & Indeterminate & 28 & 124 \\
2 & TM130802 & Jepang & Cherry & Indeterminate & 28 & 124 \\
3 & TM130803 & Jepang & Cherry & Indeterminate & 28 & 124 \\
4 & TM130804 & Jepang & Cherry & Indeterminate & 28 & 124 \\
5 & TM130805 & Perancis & Cherry & Indeterminate & 30 & 124 \\
6 & TM130806 & Jepang & Cherry & Indeterminate & 28 & 124 \\
7 & TM130807 & Bintang Asia & Rampai & Determinate & 31 & 92 \\
8 & TM130808 & Lampung & Rampai & Determinate & 31 & 92 \\
\hline
\end{tabular}


Pengamatan secara visual pada penelitian ini dilakukan pada karakter warna buah, bentuk buah, warna batang dan tipe tanaman pada delapan galur/nomor tomat lokal dan introduksi. Galur tomat lokal menunjukkan bahwa buah tomat masak berwarna merah dan berbentuk bulat. Buah pada galur tomat introduksi menunjukkan bahwa dua galur berwarna kuning dan yang lainya berwarna merah. Bentuk buah pada galur tomat introduksi terbagi menjadi dua yaitu berbentuk lonjong (oblate) dan bulat (round). Delapan galur tomat yang diuji seluruhnya memiliki warna batang hijau. Pada pengamatan tipe tanaman menunjukkan bahwa seluruh galur tomat introduksi memiliki tipe tanaman yang menyebar dan dua galur tomat lokal memiliki tipe tanaman tegak (Tabel 2).

Tabel 2. Pengamatan warna buah, bentuk buah, warna batang dan tipe tanaman pada delapan galur/nomor tomat lokal dan introduksi

\begin{tabular}{lclllll}
\hline No & Galur & \multicolumn{1}{c}{ Asal } & $\begin{array}{c}\text { Warna buah } \\
\text { masak }\end{array}$ & \multicolumn{1}{c}{ Bentuk buah } & $\begin{array}{r}\text { Warna } \\
\text { batang }\end{array}$ & $\begin{array}{c}\text { Tipe } \\
\text { tanaman }\end{array}$ \\
\hline 1 & TM130801 & Jepang & Merah & Lonjong & Hijau & Menyebar \\
2 & TM130802 & Jepang & Merah & Bulat & Hijau & Menyebar \\
3 & TM130803 & Jepang & Kuning & Lonjong & Hijau & Menyebar \\
4 & TM130804 & Jepang & Kuning & Bulat & Hijau & Menyebar \\
5 & TM130805 & Perancis & Merah & Bulat & Hijau & Menyebar \\
6 & TM130806 & Jepang & Merah & Bulat & Hijau & Menyebar \\
7 & TM130807 & Bintang Asia & Merah & Bulat & Hijau & Tegak \\
8 & TM130808 & Lampung & Merah & Bulat & Hijau & Tegak \\
\hline
\end{tabular}

\section{Tinggi tanaman}

Tinggi tanaman tomat yang diuji dapat dibedakan ke dalam dua kelompok, kelompok pertama memiliki tinggi tanaman 56-57,33 cm yaitu pada galur tomat lokal, kelompok kedua yaitu galur tomat introduksi dengan tinggi tanaman 177,67-200,33 cm (Tabel 3). Tanaman pada kelompok pertama termasuk ke dalam tipe determinate dan kelompok kedua tergolong indeterminate. Perbedaan tinggi tanaman dipengaruhi oleh faktor genetik dari masing-masing galur/nomor dan lingkungan antara lain intensitas cahaya, temperatur, dan ketersediaan unsur hara.

\section{Jumlah buah dan Jumlah tandan}

Berdasarkan analisis statistik menunjukkan perbedaan yang nyata antara beberapa galur tomat lokal dan introduksi. Berdasarkan data jumlah buah pertandan menunjukkan bahwa galur tomat lokal memiliki jumlah buah pertandan 6.33-7,67, sedangkan galur tomat introduksi memiliki jumlah buah pertandan 21,33-31,33. Jumlah tandan pertanaman menunjukkan bahwa galur tomat lokal memiliki jumlah tandan pertanaman 7,33-8,67, sedangkan galur tomat introduksi memiliki jumlah tandan lebih banyak yaitu 11,67-16,33. Data jumlah buah pertanaman menunjukkan bahwa galur introduksi TM 130805 memiliki jumlah buah pertanaman terbanyak yaitu 511,78, sedangkan galur tomat lokal TM 130807 memiliki jumlah buah pertanaman paling sedikit yaitu 54,89 (Tabel 3).

Perbedaan jumlah buah antargalur cenderung disebabkan oleh interaksi antara genotipe dan lingkungan. Variasi lingkungan terbagi dalam dua kelompok. Pertama adalah variasi lingkungan yang dapat dikendalikan, meliputi sifat-sifat umum seperti iklim dan tipe tanah. Golongan kedua, yaitu variasi lingkungan yang sukar dikendalikan, seperti fluktuasi cuaca yang meliputi jumlah curah hujan dan temperatur. Jadi karakter-karakter yang terdapat pada tanaman secara terus menerus akan memberikan tanggapan dan penyesuaian terhadap lingkungannya, sehingga terjadi perbedaan antara yang satu dengan yang lainnya (Suryadi dan Permadi, 1998). 
Tabel 3. Pengamatan tinggi tanaman, jumlah buah/tandan, jumlah buah/tandan dan jumlah buah/tanaman pada delapan galur/nomor tomat lokal dan introduksi

\begin{tabular}{ccccccc}
\hline No & Galur & Asal & $\begin{array}{c}\text { Tinggi } \\
\operatorname{tanaman}(\mathrm{cm})\end{array}$ & $\begin{array}{c}\text { Jumlah } \\
\text { buah/Tandan }\end{array}$ & $\begin{array}{c}\text { Jumlah } \\
\text { tandan/ } \\
\text { tanaman }\end{array}$ & $\begin{array}{c}\text { Jumlah buah/ } \\
\text { tanaman }\end{array}$ \\
\hline 1 & TM130801 & Jepang & $196,33 \mathrm{~b}$ & $22,67 \mathrm{bc}$ & $12,33 \mathrm{~b}$ & $279,56 \mathrm{~b}$ \\
2 & TM130802 & Jepang & $182,33 \mathrm{c}$ & $21,33 \mathrm{c}$ & $13,00 \mathrm{~b}$ & $277,33 \mathrm{~b}$ \\
3 & TM130803 & Jepang & $181,67 \mathrm{c}$ & $22,33 \mathrm{~b}$ & $11,67 \mathrm{~b}$ & $260,56 \mathrm{~b}$ \\
4 & TM130804 & Jepang & $177,67 \mathrm{~d}$ & $25,33 \mathrm{~b}$ & $12,33 \mathrm{~b}$ & $312,44 \mathrm{~b}$ \\
5 & TM130805 & Perancis & $200,33 \mathrm{a}$ & $31,33 \mathrm{a}$ & $16,33 \mathrm{a}$ & $511,78 \mathrm{a}$ \\
6 & TM130806 & Jepang & $179,33 \mathrm{~cd}$ & $30,33 \mathrm{a}$ & $13,00 \mathrm{~b}$ & $394,33 \mathrm{a}$ \\
7 & TM130807 & Bintang Asia & $56,00 \mathrm{e}$ & $6,33 \mathrm{~d}$ & $8,67 \mathrm{c}$ & $54,89 \mathrm{~d}$ \\
8 & TM130808 & Lampung & $57,33 \mathrm{e}$ & $7,67 \mathrm{~d}$ & $7,33 \mathrm{c}$ & $56,22 \mathrm{~d}$ \\
\hline
\end{tabular}

Ket : Angka yang diikuti dengan huruf yang sama menunjukkan tidak berbeda nyata menurut uji BNT pada taraf $5 \%$.

\section{Bobot buah dan Ukuran buah}

Analisis statistik pada bobot buah dan ukuran buah menunjukkan perbedaan yang nyata antara galur tomat lokal dan introduksi. Galur tomat lokal memiliki bobot perbuah 5,80-8,03 g dan bobot buah pertanaman 318.36-451,65 g, sedangkan galur tomat introduksi memiliki bobot per buah 4,03$5,27 \mathrm{~g}$ dan bobot buah pertanaman 1.076,96-2./695.36 g. Ukuran buah pada galur tomat lokal memiliki panjang 3,83-5,80 cm dan diameter 3,57-5,50 cm, sedangkan ukuran buah pada galur tomat introduksi memiliki panjang 2,15-2,47 cm dan diameter 2,17-2,26 cm (Tabel 4).

Tabel 4. Pengamatan bobot buah dan ukuran buah pada delapan galur/nomor tomat lokal dan introduksi

\begin{tabular}{|c|c|c|c|c|c|c|}
\hline \multirow{2}{*}{ No } & \multirow{2}{*}{ Galur } & \multirow{2}{*}{ Asal } & \multirow{2}{*}{$\begin{array}{c}\text { Bobot/ buah } \\
\text { (g) }\end{array}$} & \multirow{2}{*}{$\begin{array}{l}\text { Bobot buah/ } \\
\text { tanaman }(\mathrm{g})\end{array}$} & \multicolumn{2}{|c|}{ Ukuran buah } \\
\hline & & & & & Panjang $(\mathrm{cm})$ & Diameter $(\mathrm{cm})$ \\
\hline 1 & TM130801 & Jepang & $4,54 \mathrm{de}$ & $1.268,25 \mathrm{de}$ & $2,47 \mathrm{c}$ & $2,26 \mathrm{c}$ \\
\hline 2 & TM130802 & Jepang & $4,03 \mathrm{e}$ & $1.118,58 \mathrm{e}$ & $2,23 \mathrm{c}$ & $2,26 \mathrm{c}$ \\
\hline 3 & TM130803 & Jepang & $4,13 \mathrm{e}$ & $1.076,96 \mathrm{e}$ & $2,50 \mathrm{c}$ & $2,19 \mathrm{c}$ \\
\hline 4 & TM130804 & Jepang & $5,13 \mathrm{c}$ & $1.603,88 \mathrm{c}$ & $2,15 \mathrm{c}$ & $2,17 \mathrm{c}$ \\
\hline 5 & TM130805 & Perancis & $5,27 \mathrm{bc}$ & $2.695,36 \mathrm{bc}$ & $2,43 \mathrm{c}$ & $2,33 \mathrm{c}$ \\
\hline 6 & TM130806 & Jepang & $4,87 \mathrm{~cd}$ & $1.919,09 \mathrm{~cd}$ & $2,35 \mathrm{c}$ & $2,34 \mathrm{c}$ \\
\hline 7 & TM130807 & Bintang Asia & $5,80 \mathrm{~b}$ & $318,36 \mathrm{~b}$ & $3,83 \mathrm{~b}$ & $3,57 \mathrm{~b}$ \\
\hline 8 & TM130808 & Lampung & $8,03 \mathrm{a}$ & $451,65 \mathrm{a}$ & $5,80 \mathrm{a}$ & $5,50 \mathrm{a}$ \\
\hline
\end{tabular}

Ket : Angka yang diikuti dengan huruf yang sama menunjukkan tidak berbeda nyata menurut uji BNT pada taraf $5 \%$.

Ukuran buah khususnya diameter buah lebih banyak dipengaruhi oleh sifat genetik tanaman walaupun pertumbuhan dan perkembangan daun dipengaruhi oleh lingkungan, antara lain intensitas cahaya, temperatur, dan ketersediaan unsur hara, terutama unsur Nitrogen dan Phospat (Sutapradja dan Sumarni, 1996).

\section{Galur terpilih}

Berdasarkan data deskripsi dan hasil seleksi karakter tinggi tanaman, jumlah buah, bobot buah dan ukuran buah maka terpilih tiga galur tomat introduksi yang memiliki bentuk buah bulat yaitu TM 
130804, TM 130805 dan TM 130806 serta dua galur tomat introduksi yang memiliki bentuk buah lonjong yaitu TM 130801 dan TM 130803.

\section{KESIMPULAN}

Berdasarkan hasil pengamatan pada delapan galur tomat lokal dan introduksi yang telah terdeskripsi maka terpilih tiga galur tomat introduksi yang memiliki bentuk buah bulat serta dua galur tomat introduksi yang memiliki bentuk buah lonjong yang dapat digunakan sebagai bahan pemuliaan pada tahap berikutnya.

\section{DAFTAR PUSTAKA}

Duriat, A.S. 1997. Tomat Andalan yang Prospektif. Teknologi Produksi Tomat. Balai Penelitian Tanaman Sayuran. Pusat Penelitian dan Pengembangan Hortikultura. Badan Penelitian dan Pengembangan Pertanian. hal. 1-8.

Jones, B Jr. 2008. Tomato Plant Culture. In the field, Greenhouse and Home garden. CRC Press. New York. 399 p.

Nurtika, N. dan H. Suwandi. 1992. Pengaruh pemberian kapur dan sumber pupuk nitrogen terhadap pertumbuhan dan hasil tomat. Bul. Pen. Hort. XXII(4):16-21.

Suryadi dan Permadi. 1998. Evaluasi Pertumbuhan dan Daya Hasil Delapan Kultivar Kubis Bunga di Dataran Medium. J. Hort. 8(2):1068-1071.

Sutapradja, H. dan N. Sumarni. 1996. Pengaruh Dosis Pengapuran dan Kombinasi Pupuk N dan P terhadap pertumbuhan dan hasil tomat. J. Hort. (3):263-268.

Yusdar, H., Suwandi, dan N. Nurtika. 1992. Pengaruh Kombinasi Bahan Organik dan Fosfat Terhadap Pertumbuhan dan Hasil Buah Tomat pada Tanah Latosol di Dataran Rendah. Bul. Pen. Hort. XXII(4):5-15. 